Sciences, State University of Rio de Janeiro, Rio de Janeiro, Brazil; ${ }^{6}$ Clinical Immunology Unit, Dept. of Medicine, Hosp. de Santo António (HSA), Centro Hospitalar do Porto (CHP), Instituto de Ciências Biomédicas Abel Salazar (ICBAS), Univ. do Porto, Porto, Portugal; ${ }^{7}$ Radiology Unit, Dept. of Radiology, Hosp. de Santo António (HSA), Centro Hospitalar do Porto (CHP), Instituto de Ciências Biomédicas Abel Salazar (ICBAS), Univ. do Porto, Porto, Portugal

Background: Scleroderma-associated interstitial lung disease (SSc-ILD) is often observed in patients with systemic scleroderma (SSc) and its diagnosis contributes to early treatment decisions ${ }^{1,2}$.

Objectives: The present study aims to automatically quantify SSc-ILD from high-resolution chest-computed tomography (HRCT) and to evaluate the association between interstitial lung disease (ILD) extension and lung function impairment. Methods: Ninety-four patients with SSc and 27 lung-healthy subjects matched for gender, weight, height, and age underwent HRCT, spirometry and carbon monoxide diffusion capacity $\left(\mathrm{DL}_{\mathrm{CO}}\right)$. SSc-ILD was determined as the tissue mass present between -500 and +100 Hounsfield Units normalized by the total lung tissue mass (TLM). Cut off was the highest value obtained in the control group ( $25 \%$ of TLM). All data are presented as mean and standard deviations (Table I). An ANOVA test followed by Bonferroni post-hoc correction was used for comparisons among groups. Results: From 94 patients with SSc, 64 were classified as having pulmonary involvement (SSc-ILD) and 30 as not having pulmonary involvement (SSc No-ILD). In SSc-ILD subjects, there was a significant reduction in forced vital capacity (FVC), carbon monoxide diffusion capacity $\left(\mathrm{DL}_{\mathrm{co}}\right)$ and carbon monoxide diffusion capacity normalized by alveolar ventilation ( $\left.\mathrm{DL}_{\mathrm{co}} / \mathrm{A}\right)$ when compared with SSc No-ILD and control group.

Conclusion: The proposed method allows the automatic quantification of SScILD from HRCT and ILD extent is associated with pulmonary function impairment. References:

[1] Doyle TJ, Dellaripa PF. Lung Manifestations in the Rheumatic Diseases. CHEST. 2017 Dec;152(6):1283-95

[2] Saketkoo LA, Magnus JH, Doyle MK. The primary care physician in the early diagnosis of systemic sclerosis: the cornerstone of recognition and hope. The American Journal of the Medical Sciences. 2014 Jan;347(1):54-63.

Table 1. Demographic variables, pulmonary function tests and densitovolumetry considering scleroderma patients with less or greater pulmonary involvement.

\begin{tabular}{|c|c|c|c|c|}
\hline & $\begin{array}{c}\text { Control Group } \\
\qquad N=27\end{array}$ & $\begin{array}{c}\text { SSc No-ILD } \\
\qquad \begin{array}{c}\mathrm{N}=30\end{array}\end{array}$ & $\begin{array}{c}\text { SSc-ILD } \\
N=64\end{array}$ & p-value \\
\hline \multicolumn{5}{|l|}{ Demographic Data } \\
\hline Females & $16(59.2)$ & 28 (93.3) & $58(90.1)$ & - \\
\hline Age (years) & $37.9 \pm 14.8$ & $51.2 \pm 12.2$ & $56 \pm 14$ & $<0.011^{a, b}$ \\
\hline BMI $\left(\mathrm{kg} / \mathrm{m}^{2}\right)$ & $26.7 \pm 5.1$ & $24.1 \pm 5.0$ & $25.9 \pm 5.7$ & - \\
\hline \multicolumn{5}{|l|}{ Lung Function } \\
\hline FVC (\% predicted) & $100.2 \pm 9.2$ & $99.9 \pm 19.8$ & $69.8 \pm 16.7$ & $<0.001^{b, c}$ \\
\hline DLco (\% predicted) & $103 \pm 13.3$ & $83.8 \pm 14.2$ & $63.4 \pm 20.3$ & $<0.002^{\mathrm{a}, \mathrm{b}, \mathrm{c}}$ \\
\hline DLco/A (\% predicted) & $112.7 \pm 17.4$ & $85.7 \pm 12.9$ & $79.2 \pm 20.6$ & $<0.001^{\mathrm{a}, \mathrm{b}}$ \\
\hline \multicolumn{5}{|l|}{ Densitovolumetry } \\
\hline TLV mL & $4675 \pm 986$ & $4471 \pm 916$ & $3492 \pm 1120$ & $<0.001^{b, c}$ \\
\hline $\begin{array}{l}\text { Lung Tissue Mass (g) } \\
\text { ILD Extent (\% LTM) }\end{array}$ & $\begin{array}{c}793 \pm 125 \\
17 \pm 2\end{array}$ & $\begin{array}{l}756 \pm 159 \\
22.9 \pm 1.2\end{array}$ & $\begin{array}{c}731 \pm 155 \\
32.6 \pm 8\end{array}$ & $<0 . \overline{-}$ \\
\hline
\end{tabular}

a: Statistically significant difference between No-ILD SSc and control group; $b$ and c: Statistically significant difference between SSc-ILD vs control group and SSc No-ILD, respectively.

Disclosure of Interests: None declared

DOI: 10.1136/annrheumdis-2020-eular.1641

\section{AB0562 2 SLEEP HYGIENE: COULD IT BE A CONFOUNDING FACTOR FOR SLEEP QUALITY IN SYSTEMIC SCLEROSIS?}

N. Gokcen ${ }^{1}$, A. Komac ${ }^{1}$, F. Tuncer ${ }^{1}$, A. Yazici ${ }^{1}$, A. Cefle ${ }^{1} .{ }^{1}$ Kocaeli Üniversitesi Tıp Fakültesi, Department of Internal Medicine, Division of Rheumatology, Kocaeli, Turkey

Background: Sleep disturbances have been described in Systemic Sclerosis (SSc). Confounding factors related to sleep quality are also investigated. Although sleep hygiene plays an important role in sleep quality, as far as we know, there are not enough data to show the effect of sleep hygiene on sleep quality of SSc.

Objectives: To investigate sleep hygiene, its impact on sleep quality, and its association with demographic-clinical factors in patients with SSc, rheumatoid arthritis (RA), and healthy controls.

Methods: The study was designed as cross-sectional. Forty-nine patients with SSc who fulfilled the 2013 ACR/EULAR classification criteria for SSc, 66 patients with RA who fulfilled 1987 revised classification criteria, and 30 healthy controls were included in the study. All participants were female. Demographic and clinical variables were documented. Disease activity index of both SSc and RA was calculated. SSc patients were assessed by questionnaires including Short Form 36 (SF-36), The Health Assessment Questionnaire Disability Index (HAQ-DI), Beck Anxiety and Beck Depression Inventory, Pittsburg Sleep Quality Index (PSQI) Sleep Hygiene Index (SHI). Additionally, RA patients and healthy controls were estimated by HAQ-DI, Beck Anxiety and Beck Depression Inventory, PSQI, and $\mathrm{SHI}$. Logistic regression analysis was used to determine the predictors of sleep quality.

Results: Preliminary results of the study were given. The baseline demographics were similar among groups. When comparing groups according to HAQ-DI, Beck Anxiety and Beck Depression Inventory, PSQI, and SHI, we found higher scores in SSc and RA rather than healthy controls $(p<0.001, p=0.001, p=0.001$ $p<0.001, p=0.003$; respectively). While depression and sleep hygiene were determined as the risk factors of sleep quality in SSc in univariate analysis, depression $(\mathrm{OR}=1.380,95 \% \mathrm{Cl}: 1.065-1.784, \mathrm{p}=0.015)$ and sleep hygiene $(\mathrm{OR}=1.201$ $95 \% \mathrm{Cl}$ : $1.003-1.439, \mathrm{p}=0.046)$ were also found in multivariate logistic model In RA patients, while health status, depression, and anxiety were found as risk factors according to the univariate analysis, depression $(O R=1.120,95 \% \mathrm{Cl}$ : 1.006-1.245, $\mathrm{p}=0.038$ ) was the only factor according to multivariate logistic model (Table).

Conclusion: Although depression is a well-known clinical variable impacting on sleep quality, sleep hygiene should also be kept in mind as a confounding factor.

\section{References:}

[1] Milette K, Hudson M, Körner A, et al. Sleep disturbances in systemic sclerosis: evidence for the role of gastrointestinal symptoms, pain and pruritus. Rheumatology (Oxford). 2013 Sep;52(9):1715-20.

[2] Sariyildiz MA, Batmaz I, Budulgan M, et al. Sleep quality in patients with systemic sclerosis: relationship between the clinical variables, depressive symptoms, functional status, and the quality of life. Rheumatol Int. 2013 Aug;33(8):1973-9.

Table. Univariate logistic regression analysis of clinical variables to assess predictors of sleep quality

\begin{tabular}{lcccc}
\hline & Systemic sclerosis & \multicolumn{3}{c}{ Rheumatoid arthritis } \\
\hline & OR $(95 \% \mathrm{Cl})$ & $\mathrm{p}$ & OR $(95 \% \mathrm{Cl})$ & $\mathrm{p}$ \\
\hline HAQ-DI & $1.019(0.882-1.177)$ & 0.801 & $1.089(1.011-1.173)$ & $\mathbf{0 . 0 2 5}$ \\
BDI score & $1.293(1.082-1.547)$ & $\mathbf{0 . 0 0 5}$ & $1.129(1.036-1.230)$ & $\mathbf{0 . 0 0 6}$ \\
BAI score & $1.080(0.997-1.169)$ & 0.059 & $1.122(1.038-1.214)$ & $\mathbf{0 . 0 0 4}$ \\
SHI & $1.200(1.060-1.357)$ & $\mathbf{0 . 0 0 4}$ & $1.048(0.965-1.137)$ & 0.264 \\
Disease activity $^{\mathrm{a}}$ & $0.707(0.439-1.138)$ & 0.153 & $1.446(0.839-2.492)$ & 0.185 \\
\hline
\end{tabular}

${ }^{a}$ Disease activity was calculated by Valentini disease activity index for SSc and DAS28-CRP for RA.

Disclosure of Interests: None declared

DOI: 10.1136/annrheumdis-2020-eular.3477

\section{AB0563 AORTIC ROOT DILATION IN ASSOCIATED WITH THE REDUCTION OF CAPILLARY DENSITY OBSERVED AT NAILFOLD CAPILLAROSCOPY IN SSC PATIENTS}

M. Colaci ${ }^{1}$, Y. Dal Bosco ${ }^{2}$, C. Schinocca ${ }^{2}$, M. L. Aprile ${ }^{2}$, G. Guggino ${ }^{3}$, I. De Andres $^{4}$, A. A. Russo ${ }^{5}$, G. Sambataro ${ }^{6}$, D. Sambataro ${ }^{7}$, L. Malatino ${ }^{6} .{ }^{1}$ University of Catania, Clinical and Experimental Medicine, Catania, Italy; ${ }^{2}$ Rheumatology Centre, Ospedale Cannizzaro, Catania, Italy; ${ }^{3}$ University of Palermo, Palermo, Italy; ${ }^{4}$ Rheumatology Unit, Ospedale Garibaldi Centro, Catania, Italy; ${ }^{5}$ Rheumatology Unit, Ospedale Garibaldi Centro, Ctania, Italy; ${ }^{6}$ University of Catania, Catania, Italy; ${ }^{6}$ University of Catania, Catania, Italy

Background: Systemic sclerosis (SSc) in a chronic autoimmune disease characterized by endothelial dysfunction and diffuse microangiopathy, leading to tissue ischemia and inducing fibrosis of skin and visceral organs. Furthermore it was demonstrated the impairment of wall elasticity of large-medium vessels, such as aorta and its branches (1). SSc-related microangiopathy of vasa vasorum of the aortic wall could also be supposed. However no data on this hypothesis are available in literature.

SSc microangiopathy may be easily studied at the nailfold by means of videocapillaroscopy. Indeed, capillaroscopic findings are representative of the microvascular damage caused by SSc troughout the body.

Objectives: we aimed to investigate the presence of aortic root dilation, classica sign of aortic wall damage, in a cohort of SSc patients, and to correlate these 
findings with the capillaroscopic patterns (early, active, and late, according to Cutolo's classification (2))

Methods: we recruited 125 SSc patients (M/F: 14/111, mean age 55+/-12.7 years, median disease duration 11 years) in 3 Rheumatology Centres in Sicily, Italy, from January to December 2019.

Transthoracic echocardiogram with aortic root diameter measurement was carried out in all patients. Moreover, videocapillaroscopy with identification of early, active, or late SSc patterns was performed in the whole case series. Patients with early SSc pattern formed the subgroup 1, while those with the active or late patterns (both characterized by the reduction of capillary density) the subgroup 2.

Results: we identified 8 (6.4\%) SSc patients with aortic root dilation (diameter > $35 \mathrm{~mm}$ ). Their age and their frequencies of cardiovascular risk factors were similar to the whole series. Moreover, videocapillaroscopy showed $62(49.6 \%)$ early, $47(37.6 \%)$ active, and $16(12.8 \%)$ late SSc patterns.

Aortic root dilation was observed in only one patient in the subgroup $1(1 / 62$, $1.6 \%)$, and in 7 cases of the subgroup $2(7 / 63,11.1 \%) ; p=0.03$.

Conclusion: in this multicentre study, we found that aortic root dilation is significantly associated with the reduction of capillary density at nailfold capillaroscopy (active or late SSc patterns). On the basis of these findings, we might argue that SSc-related microangiopathy of vasa vasorum could contribute to aortic wall damage, at least in a subset of SSc patients.

References:

[1] Bartoloni E, Pucci G, Cannarile F, Battista F, Alunno A, Giuliani M, Cafaro G, Gerli R, Schillaci G. Central hemodynamics and arterial stiffness in systemic sclerosis. Hypertension 2016; 68:1504-1511. 2.Cutolo M, Matucci-Cerinic M. Nailfold capillaroscopy and classification criteria for systemic sclerosis. Clin Exp Rheumatol 2007; 25:663-665

Disclosure of Interests: Michele Colaci: None declared, Ylenia Dal Bosco: None declared, Claudia Schinocca: None declared, Maria Letizia Aprile: None declared, Giuliana Guggino Grant/research support from: Pfizer, Celgene, Speakers bureau: Celgene, Sandoz, Pfizer, Ilenia De Andres: None declared, Alessandra Azzurra Russo: None declared, Gianluca Sambataro: None declared, Domenico Sambataro: None declared, Lorenzo Malatino: None declared DOI: 10.1136/annrheumdis-2020-eular.3156

\section{AB0564 HEART VALVULAR ALTERATIONS IN A MULTICENTRE ITALIAN COHORT OF SSC PATIENTS}

M. Colaci ${ }^{1}$, C. Schinocca ${ }^{2}$, Y. Dal Bosco3, M. L. Aprile3, G. Guggino ${ }^{4}$, I. De Andres ${ }^{5}$, A. A. Russo ${ }^{5}$, D. Sambataro ${ }^{1}$, G. Sambataro ${ }^{1}$, L. Malatino ${ }^{1}$. ${ }^{1}$ University of Catania, Catania, Italy; ${ }^{2}$ Rheumatology Centre, Ospedale Cannizzaro, Catania, Italy; ${ }^{2}$ Rheumatology Centre, Ospedale Cannizzaro, Catania, Italy; ${ }^{4}$ University of Palermo, Palermo, Italy; ${ }^{5}$ Ospedale Garibaldi Centro, Catania, Italy

Background: systemic sclerosis (SSc) in a chronic autoimmune disease characterized by endothelial dysfunction, diffuse microangiopathy, and fibrosis of skin and visceral organs. Typical cardiac involvement may includes microvascular ischemia, contraction band necrosis, and patchy fibrosis, leading mainly to arrythmias and conduction defects, diastolic dysfunction, or right ventricular failure (secondary to pulmonary arterial hypertension) [1]. Valvular diseases are poorly described and generally not considered a typical sign of SSc [2-4].

Objectives: we aimed to describe valvular alterations in a multicentre cohort of SSc patients.

Methods: we consecutively recruited 118 SSc patients (M/F: 14/104, mean age $56.7 \pm 12.4$ years, median disease duration 10 years, limited/diffuse skin subsets: 95/23, anti-centromere/anti-Scl70/others autoantibodies: 35/37/46) in 3 Rheumatology Centres in Sicily, Italy, from January to December 2019.

Considering the cardiovascular risk factors, 40 (34\%) patients were smokers, 7 $(6 \%)$ diabetics, 12 (10\%) showed hypercholesterolemia, $38(32 \%)$ arterial hypertension, while none was obese. Transthoracic echocardiogram was carried out in all patients during their follow-up.

Results: valvular abnormalities were as follow: mitral valve: insufficiency 85 $(72 \%)$ cases - mild in $77 / 85$, stenosis $2(2 \%)$ - mild in $25 / 28$, sclerosis/tickening $36(30 \%)$, and calcification $9(8 \%)$ patients; aortic valve: insufficiency 28 $(24 \%)$, stenosis $4(3 \%)$, sclerosis $29(25 \%)$, and calcification $7(6 \%)$ patients; tricuspid valve: insufficiency $91(77 \%)$ cases, no cases of stenosis, sclerosis $5(4 \%)$, and calcification $1(1 \%)$ patients; pulmonary valve: insufficiency in 13 (11\%) patients.

As expected, tricuspid insufficiency (TI) was associated with pulmonary arterial hypertension (PAH) (moderate $\mathrm{TI}$ in $20 \%$ of patients with every $\mathrm{TI}$ and $\mathrm{PAH}$ vs. $4 \%$ of patients with $\mathrm{TI}$ without $\mathrm{PAH}, \mathrm{p}=0.019$ ).
Aortic sclerosis (AS) was associated with the presence of arthritis (AS in 35\% of patients with arthritis vs. $16 \%$ of patients without, $p=0.029$ )

No association was found with age, gender, disease duration, skin subset, autoantibodies, capillaroscopic patterns, presence of digital ulcers, lung, renal, or digestive involvements

Conclusion: in this multicentre SSc cohort study, we found that cardiac valve alterations are very common, even though generally not clinically relevant. The presence of PAH was associated with more severe TI. Finally, AS was associated with arthritis that could be considered sign of chronic inflammatory state, which is often linked with accelerated atherosclerosis and remodeling process of aortic valve [5].

\section{References:}

[1] Lambova S. Cardiac manifestations in systemic sclerosis. World J Cardio 2014; 6:993-1005.

[2] D’Angelo W, Fries JF, Masi AT, Shulman LE. Pathologic observations in systemic sclerosis (scleroderma).A study of fifty-eight autopsy cases and fifty-eight matched controls. Am J Med 1969; 46:428-440.

[3] Kazzam E, Caidahl K, Hallgren R, et al. Mitral regurgitation and diastolic flow profile in systemic sclerosis. Int J Cardiol 1990; 29:357-363

[4] Wranicz J, Zielińska M, Cygankiewicz I, et al. Early cardiovascular involvement in patients with systemic sclerosis (SSc). Med Sci Monit. 2002 8:CR78-82.

[5] Coté N, Mahmut A, Bosse $Y$, et al. Inflammation is associated with remodeling of calcific aortic valve disease. Inflammation 2013; 36:573-581.

Disclosure of Interests: Michele Colaci: None declared, Claudia Schinocca: None declared, Ylenia Dal Bosco: None declared, Maria Letizia Aprile: None declared, Giuliana Guggino Grant/research support from: Pfizer, Celgene Speakers bureau: Celgene, Sandoz, Pfizer, Ilenia De Andres: None declared, Alessandra Azzurra Russo: None declared, Domenico Sambataro: None declared, Gianluca Sambataro: None declared, Lorenzo Malatino: None declared

DOI: 10.1136/annrheumdis-2020-eular.4348

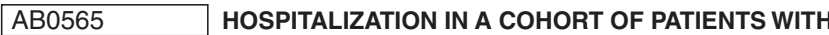 IDIOPATHIC INFLAMMATORY MYOPATHY: WHAT IS HAPPENING IN ARGENTINA?}

F. Arizpe ${ }^{1}$, M. Cosentino ${ }^{1}$, A. C. Costi ${ }^{1}$, V. Martire ${ }^{1}$, A. Testi ${ }^{1}$, M. García ${ }^{1} .{ }^{1}$ HIGA San Martin, La Plata, Argentina

Background: Inflammatory myopathies are rare diseases that affect multiple organs and systems, with poor prognosis and high in-hospital mortality. ${ }^{(1,2)}$ In Argentina there are few reported data regarding hospitalization and its outcomes in these patients.

Objectives: To analyze the characteristics of hospitalizations and the factors associated with poor outcome in adult patients with Idiopathic Inflammatory Myopathy (IIM)

Methods: Retrospective, analytical study. We included patients $\geq 18$ years with IIM, according to Bohan and Peter and/or ACR / EULAR 2017 criteria, who were admitted in our hospital between 2003 and 2019 at least once. Sociodemographic and clinical data were recorded. We defined "unfavorable outcome" as the presence of one of the following events: death, mechanical respiratory assis tance and/or critical care unit requirement. Continuous variables were compared by Student's or Mann Whitney's T test, and categorical variables by Chi ${ }^{2}$ test or Fisher's exact test. Binary logistic regression was performed to identify independent factors associated with an unfavorable outcome.

Results: 61 hospitalizations of 40 patients with IIM were evaluated; $67.5 \%$ of the patients were female $(27 / 40)$, with a mean age of 52.5 years $(S D \pm 13)$. The most frequent reason of admission was for diagnosis (44.3\%) followed by disease activity (31.1\%). In $78.7 \%$ of hospitalizations (48/61) the diagnosis was dermatomyositis. The median of hospitalization days was 14 (IQR 8-30). In 21 out of 61 hospitalizations (34.4\%), an unfavorable outcome was observed, of which $17(80.9 \%)$ ended in death. Respiratory muscle involvement $(p=0.01)$, thrombocytopenia $(p<0.001)$, treatment with intravenous methylprednisolone pulses $(p=0.032)$, Intravenous Immunoglobulin $(p=0.001)$, longer hospitalization ( $=0.001)$ and severe infections $(p=0.001)$ were associated with adverse outcomes. In the multivariate analysis, serious infections (OR: 21.7; IC95 1.77 - 266 $\mathrm{p}=0.016$ ) and the requirement of Intravenous Immunoglobulin (IVIg) (OR: 54.5 IC95 $1.4-214 ; p=0.033$ ) were found to be independently associated with an unfavorable outcome.

Conclusion: IIMs are diseases with high morbidity and mortality rate. In this cohort of hospitalized patients, we found a high percentage of unfavorable outcomes. Seriously ill patients received IVIg more frequently, and severe infections were associated with worse prognosis. 